\title{
Exploring the contribution of proximal family risk factors on SLC6A4 DNA methylation in children with a history of maltreat-
}

\section{ment}

\author{
Francesco Craig ${ }^{*}, 1,2$, Eleonora Mascheroni ${ }^{*}$, , Roberto Giorda ${ }^{4}$, Maria Grazia Felline'; Maria Grazia Bacco ${ }^{2}$, Annalisa \\ Castagna $^{3}$, Flaviana Tenuta ${ }^{1}$, Marco Villa ${ }^{4}$, Angela Costabile ${ }^{1}$, Antonio Trabacca ${ }^{2}{ }^{* *}$, Rosario Montirosso $^{3}$
}

\author{
${ }^{1}$ Department of Culture, Education and Society, University of Calabria, Cosenza, Italy \\ ${ }^{2}$ Unit for Severe Disabilities in Developmental Age and Young Adults, Scientific Institute IRCCS Eugenio Medea, \\ Brindisi, Italy \\ 30-3 Center for the at-Risk Infant, Scientific Institute IRCCS Eugenio Medea, Bosisio Parini (Lecco), Italy \\ ${ }^{4}$ Molecular Biology Laboratory, Scientific Institute IRCCS Eugenio Medea, Bosisio Parini (Lecco), Italy \\ **Corresponding author: Scientific Institute, IRCCS Eugenio Medea - Associazione "La Nostra Famiglia", Piazza \\ A. Di Summa, 72100, Brindisi, Italy, E-mail address: antonio.trabacca@lanostrafamiglia.it \\ *These authors have contributed equally to this work.
}

\begin{abstract}
The cumulative effects of proximal family risk factors have been associated with a greater number of adverse outcomes in childhood maltreatment. DNA methylation of the serotonin transporter gene (SLC6A4) has been associated with child maltreatment. However, the relationships between proximal family risk factors and SLC6A4 methylation remains unexplored. We examined the association among cumulative family risk factors, maltreatment experiences and DNA methylation in the SLC6A4 gene in a sample of 33 children victims of maltreatment. We computed a cumulative family risk (CFR) index that included proximal family risk factors such as drug or alcohol abuse, psychopathology, parents' experiences of maltreatment/abuse in childhood, criminal history, and domestic violence. The majority of children $(90.9 \%)$ experienced more than one type of maltreatment. Hierarchical regression models suggested that greater CFR, higher number of maltreatment experiences, and children age were associated with higher SLC6A4 DNA methylation. Our findings suggest that, together with childhood maltreatment experiences per sè, cumulative proximal family risk factors seem to represent a critical condition associated with DNA methylation at the SLC6A4 gene
\end{abstract}

Keywords: cumulative family risk; child maltreatment; early adversity; DNA methylation; SLC6A4

\section{Introduction}

Childhood maltreatment includes any form of physical and/or emotional or sexual abuse, deprivation, and neglect of children, or commercial or other exploitation resulting in harm to the child's health, survival, development, or dignity [1]. It is a global phenomenon that affects the lives of millions of children. Worldwide, it is estimated that up to 1 billion children aged 2-17 years, encounter physical, sexual, or emotional violence or neglect [2]. In Italy a national survey on child maltreatment reported that 77,000 children are victims of maltreatment, 9 children per 1,000 residents [3]. Children who experience maltreatment often show emotional, behavioral, physical, and mental health problems [4-7] with serious life-long consequences on multiple developmental domains and functions [8].

Childhood maltreatment generally occurs within high-risk contexts characterized by several proximal family risk factors (i.e., direct and immediate caregivers' vulnerabilities such as drug or alcohol abuse, psychopathology, experiences of maltreatment/abuse in childhood, criminal history, domestic violence), some of which may influence both the type of maltreatment and the child's outcome $[9,10]$. Some evidence supports the hypothesis that cumulative risk (i.e., the total number of risk factors) is a stronger predictor of 
adverse and detrimental child outcomes than any individual single risk factor [11]. Multiple risk factors in the family environment may operate conjointly to predict negative developmental outcomes [12-14]. Importantly, these family risk factors are not independent of one another and often cluster within the same family environment. In fact, most of the families reported for childhood maltreatment exhibit a combination of different proximal risk factors, including parent's psychopathology, parents' experiences of abuse in childhood, domestic violence, unemployment, poverty, and substance abuse $[15,16]$. Therefore, when investigating children's bio-behavioral outcome as a consequence of adverse events, it is important to also include proximal mechanisms that link multiple family risk factors and child's health [17].

The serotoninergic system plays a key role in regulating hypothalamic-pituitaryadrenal axis (HPA) stress reactivity and its negative feedback [18,19]. Serotonin (5-HT) receptors are spread broadly throughout the central nervous system and develop early during gestation, with the serotonergic system maturing during the first year of life [20]. In humans, serotonin receptors are located in peripheral tissues as well as in the central nervous system, particularly in cerebral cortex, hippocampus, amygdala, hypothalamus, and the pituitary adrenal gland [21-23]. These brain regions are involved in the processing of socio-emotional stress regulation and are densely innervated by serotonin neurons [24]. Altered serotonergic neurotransmission affects a wide range of neurodevelopmental outcomes (e.g., behavior, cognition, emotion, and stress regulation) [25] and psychiatric disorders (e.g., mood disorders, anxiety disorders, post-traumatic stress disorder) [26]. Feedback processes through the serotonin transporter (5-HTT), which is encoded by the SLC6A4 gene [27], regulate the system. A rapidly growing body of research has highlighted the potential role of SLC6A4 DNA methylation in childhood maltreatment [28]. Several studies have reported changes in SLC6A4 DNA methylation in individuals exposed to early life adversity [25,29]. For example, higher SLC6A4 methylation was found amongst adults exposed to parental loss and parental psychopathology [30,31]. Furthermore, childhood maltreatment such as physical abuse [32,33], sexual abuse [29,34] or a combination of both [34] have been associated with SLC6A4 methylation. Furthermore, increased SLC6A4 DNA methylation has been shown in children who have experienced greater early adversity family environment, especially those from families with an alcoholic father, compared with a matched sample of control children [35]. Overall, although this evidence suggests that SLC6A4 DNA methylation might be a potential biomarker even in the case of multiple family risk factors, to the best of our knowledge, the relationships between cumulative proximal family risk factors, child maltreatment experiences (i.e., number of maltreatment reports), and SLC6A4 DNA methylation remains unexplored.

In the current study, we wanted to expand upon previous findings utilizing a broader conceptualization of childhood maltreatment that includes proximal family risk factors. As a consequence, in line with previous studies documenting that a cumulative index is a better predictor than any single independently assessed risk factor [36,37], we computed a cumulative family risk (CFR) index by summing a number of proximal family risk factors, such as drug or alcohol abuse, psychopathology, experiences of maltreatment/abuse in childhood, parents' criminal history, domestic violence [38]. A major methodological difficulty in this kind of studies is to establish whether infants' SLC6A4 methylation is affected by the severity of proximal family risk factors or by the consequences of the maltreatment experience itself. It is unclear whether the joint presence of several family risk factors, and the maltreatment experience itself act as direct predictors of altered SLC6A4 DNA methylation or whether the relationship between CFR and altered SLC6A4 DNA methylation is mediated by the number of maltreatment experiences experienced by the child. In light of these considerations, we aimed to examine both the direct (CFR ๑) altered SLC6A4 DNA methylation patterns) and indirect (CFR ๑ number of maltreatment experiences ㅇ altered SLC6A4 DNA methylation patterns) effects of CFR index 
in explaining SLC6A4 DNA methylation patterns in children victims of maltreatment. First, we expected that a greater CFR index would be associated with a higher number of maltreatment reports. Second, we hypothesized that both the CFR index and the number of lived maltreatment experiences had an effect on DNA methylation: a greater cumulative risk exposure to proximal family risk factors and a greater cumulative maltreatment experience would negatively influence (either directly or indirectly) children's SLC6A4 DNA methylation.

\section{Materials and Methods}

\subsection{Participants}

Participants were children with a history of maltreatment recruited at the Maltreatment Clinical Unit of the Scientific Institute IRCCS “Eugenio Medea” of Brindisi (Italy). All children involved were removed from their caregivers' care and placed in residential care after notification of the Juvenile Justice System. Residential care refers to long-term care given to children who stay in an institutional setting rather than in their own home or family home. Children in residential care could have contact with their birth family. This is arranged by the multidisciplinary team (i.e., child neuropsychiatrist, psychology, pedagogist, social workers, and child abuse expert consultant) of the Maltreatment Clinical Unit. Children who received preventative social services assessment because of concerns about risk of maltreatment were not included in the study sample. Further sample exclusion criteria were the presence of any genetic abnormalities, neurosensory disabilities (i.e., blindness, deafness) or medical condition (i.e., brain damage, autoimmune diseases, inflammatory bowel diseases, failure-to-thrive, and systemic cardiological complications).

The Ethical Committee of the IRCCS Giovanni Paolo II (Bari, Italy) approved the study design (Protocol number 238/18). The study was also authorized by the Juvenile Justice Section (Italian Ministry of Justice) of Lecce, Italy. All the parents or the legal guardians of the children participating to this study gave written informed consent and had the right to withdraw at any stage.

\subsection{SLC6A4 methylation assessment}

One saliva sample for epigenetic analysis was obtained from trained researchers at the Maltreatment Clinical Unit of the Scientific Institute IRCCS "Eugenio Medea" of Brindisi (Italy) during a neuropediatric medical visit. A minimum of $2 \mathrm{ml}$ of saliva was obtained either by placing a salivary swab in the child's mouth (for younger children) or by asking the child to spit into a tube (for older children). The saliva collection procedure was done non-invasively and in a stress-free manner. All samples were obtained after 30 minutes of fasting. The buccal swab was processed using the ORAcollect OC-175 kits (DNA Genotek, Ottawa, Canada) and stored at $+4^{\circ} \mathrm{C}$. Then, saliva samples were delivered to the Biology Laboratory of the Scientific Institute IRCCS "Eugenio Medea" (Bosisio Parini, Lecco). Genomic DNA was extracted following manufacturer's protocols and its quality was evaluated using a Qubit fluorometer (Invitrogen, Thermo Fisher Scientific, Waltham, Massachusetts, USA). SLC6A4 DNA methylation status was analyzed by polymerase chain reaction amplification of bisulfite-treated DNA followed by next-generation sequencing on a NEXTSeq-500 (Illumina Inc, San Diego, California, USA). A specific region of SLC6A4 was analyzed: chr17:28562750-28562958, including 13 CpG sites that have been analyzed in associations with childhood adversity [32,35,39]

\subsection{Child and family characteristics}


Information about the study participants and their family was obtained through services case records using an ad-hoc data collection checklist for detecting child gender, child age, mother and father's age, level of education, employment status, proximal family risk factors and child's maltreatment history.

\subsection{Cumulative family risk (CFR) index}

Proximal family risk factors, which included for each child both maternal and paternal risk factors for maltreatment, were taken into account for the computation of the CFR index. The selection of risk variables was based on pre-existing literature $[16,38,40-$ 42] and included: drug or alcohol abuse, psychopathology, experiences of maltreatment/abuse in childhood, parents' criminal history, perpetrators of domestic violence. Although unemployment and job insecurity are an additional and key family risk factors $[41,43]$, we did not include these variables in the CFR index because all parents were unemployed or had only occasional jobs, thus reducing the variability. Each of the 10 variables (5 for caregiver 1 and five for caregiver 2) was first categorized into a dichotomous variable: 0 = absence of risk, 1 = presence of risk. Then, for each child, the dichotomous variables were summed into a CFR index that potentially ranged from zero (absence of any risk factor) to 10 (presence of all risk factors in both caregivers).

\subsection{Child maltreatment lived experiences}

The Maltreatment Classification System (MCS) [44] was used to assess individual children's maltreatment experiences and to code the type of maltreatment children experienced based on children's records from child protective services. The MCS is a method for classifying maltreatment reports including dimensions of subtype, severity, frequency, chronicity, and perpetration of maltreatment. The MCS has shown to be a reliable and valid tool in classifying maltreatment in several studies $[45,46]$. The subtypes of maltreatment are physical abuse, sexual abuse, physical neglect (failure to provide food, shelter, clothing, hygiene, or medical care), supervisory neglect (general lack of supervision, inappropriate substitute care, or lack of supervision in a dangerous environment), emotional/psychological maltreatment, moral-legal/educational maltreatment, and drug/alcohol use. In this study, every type of maltreatment was coded for all children on a dichotomous scale $(0=$ not reported, $1=$ reported $)$. If the record did not mention any incidences of a specific maltreatment type, it was coded as not reported. All children's records were coded by two clinical psychologists blind to the aims of the paper.

\section{Results}

3.1. Sample characteristics

Participants were 33 children (20 female) aged between 8 months and 15 years $(\mathrm{M}=$ 8.26 , $\mathrm{SD}=3.63$ ) who were victims of child maltreatment. Caregivers' sociodemographic characteristics are reported in Table 1. Mean-percentage methylation for the 13 SLC6A4 CpG sites analyzed is reported in Figure 1.

Table 1. Parent's sociodemographic characteristics

\begin{tabular}{ll} 
& \multicolumn{1}{c}{$\begin{array}{l}\text { Mean, } \\
\text { Range },\end{array}$} \\
\cline { 2 - 3 } Maternal age (years) (data not available from 3 mothers) & $M=38.13, S D=7.14$, Range: $27-48$ \\
Paternal age (years) (data not available from 2 fathers) & $M=42.96, S D=8.09$, Range: $26-56$
\end{tabular}


Mothers' Level of education

Secondary school

Not known/Not available

Fathers' Level of education

Professional qualification

Primary school

Secondary school

High school

Not known/Not available

Mother employment

$$
\text { Unemployed }
$$

Occasional job

Father unemployed

Unemployed

Occasional job $n=24$

$72.7 \%$

$n=9$

$27.3 \%$

$9.1 \%$

$6.1 \%$

$45.5 \%$

$3.0 \%$

$36.3 \%$

$n=8$

$n=26$

$78.8 \%$

$21.2 \%$

$75.8 \%$

$78.5 \%$

$21.5 \%$

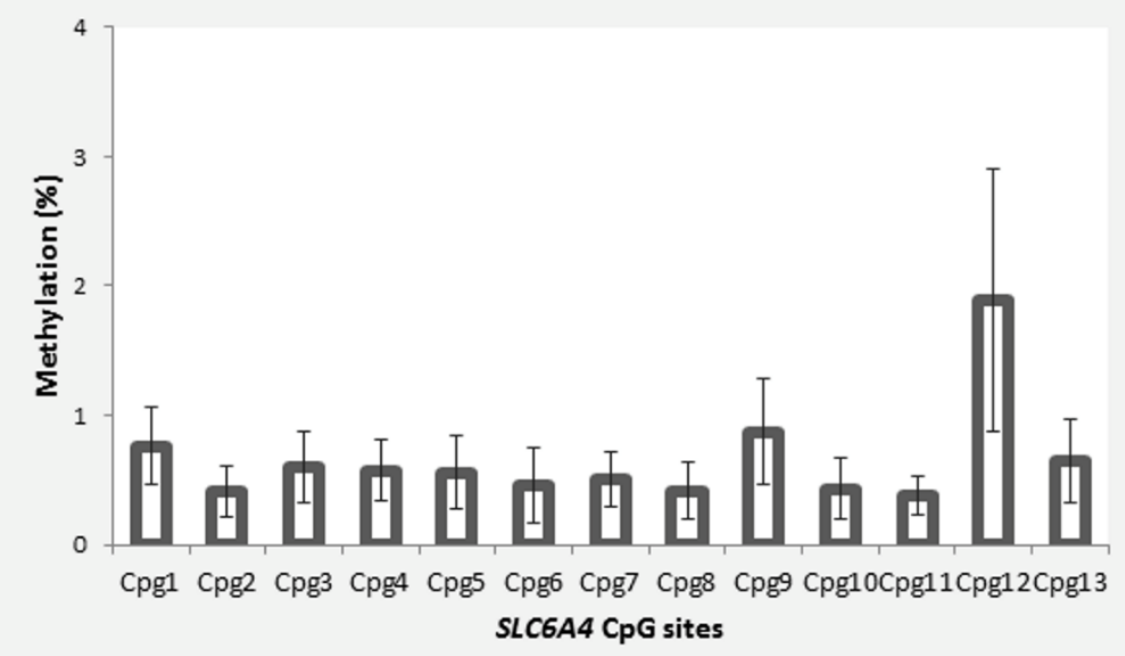

Figure 1:Site-specific SLC6A4 methylation in maltreated children from our sample. Error bars represent standard errors.

3.2. Maltreated children's experiences and family cumulative risk 
Thirty children (90.9\%) reported more than one type of childhood maltreatment. Figure 2 shows the percentage of children's cumulative maltreatment experiences. These maltreatment experiences occurred over a highly variable time frame ranging from less than one year to seven years prior to the children being placed in residential care $(\mathrm{M}=2.4, \mathrm{SD}$ $=1.8$ ). Prevalence for each maltreatment experiences is reported in Table 2 .

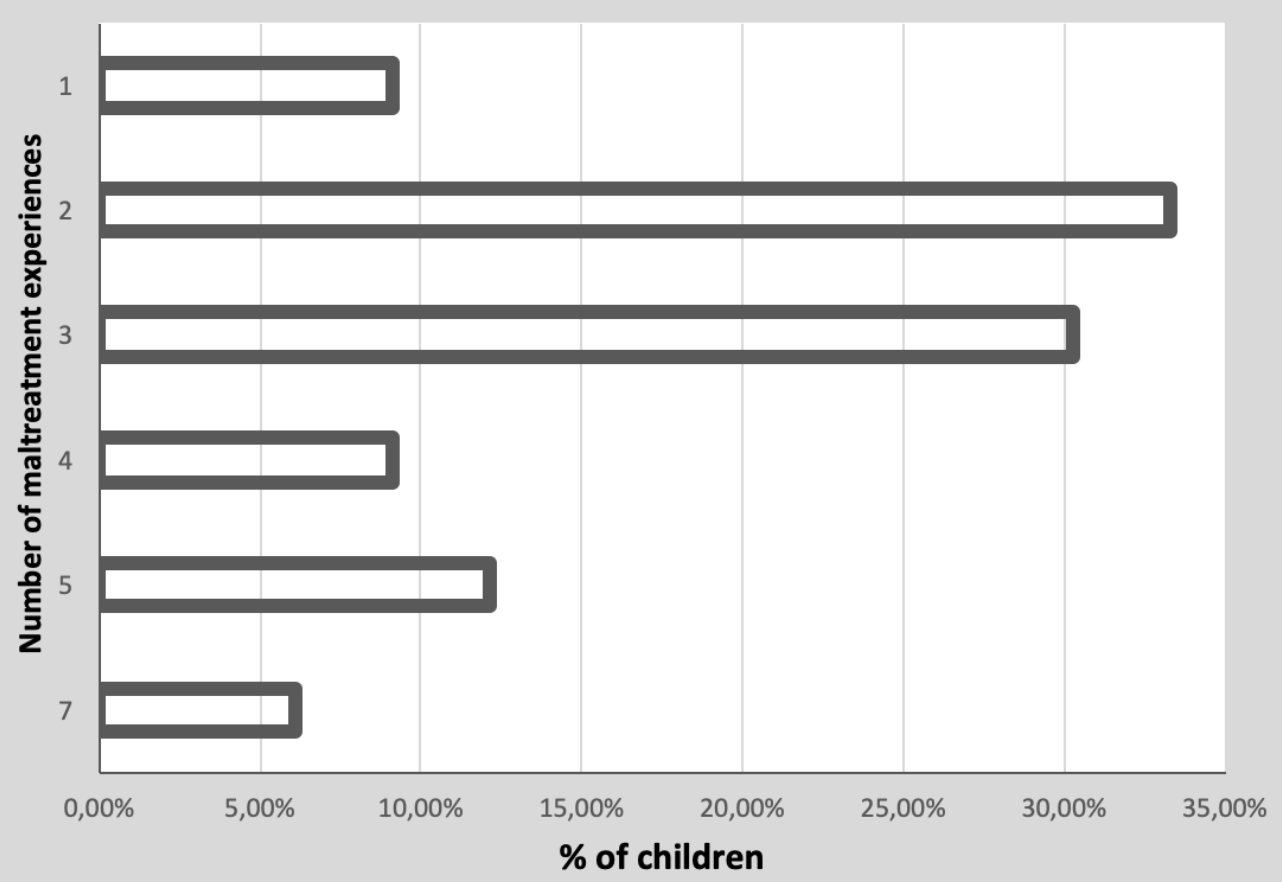

Figure 2. Prevalence (\%) for children's multiple experiences of maltreatment.

Table 2. Prevalence for children's maltreatment experiences classified with the Modified Maltreatment Classification System

Children's maltreatment experiences

Emotional maltreatment

Physical neglect

Supervision neglect

Moral neglect

Educational neglect

Physical abuse

Sexual abuse $n$

33

100

29

16

7

5

6

5

Note. The percentages sum is greater than 100 since a child may have experienced multiple types of maltreatment 
Prevalence for each proximal family risk factor is reported in Table 3. The mean CFR index was 2.91 (SD =2.26), ranging from 0 to 7 .

Table 3. Prevalence for each parents' risk variable

\section{Parents' risk variable}

Drug or alcohol abuse

Experiences of maltreatment/abuse in childhood

Psychopathology

Perpetrators of domestic violence

Criminal history $n$

23

18

14

11

8
\%

24.2

Note. The percentages sum is greater than 100 since in a single family there may be more than one proximal family risk factors

3.3. Preliminary analysis

A set of correlational analyses was performed to investigate whether: (1) a greater cumulative risk exposure to proximal family risk factors (CFR) associates with a greater number of children's maltreatment experiences (NMRs); (2) children's DNA methylation level at each CpG site in the promoter region of SLC6A4 was significantly associated with both CFR index and NMRs. Pearson's correlation revealed a non-significant association between CFR and NMRs $(r=.21 ; \mathrm{p}=.238)$. Some significant positive association between CFR index and methylation in different SLC6A4 CpGs sites emerged: higher score in the CFR index was associated to higher DNA methylation at CpG5 ( $\mathrm{r}=.61 ; \mathrm{p}<.001)$, CpG7 ( $\mathrm{r}$ $=.45 ; \mathrm{p}=.008), \mathrm{CpG8}(\mathrm{r}=.35 ; \mathrm{p}=.048), \mathrm{CpG9}(\mathrm{r}=.39 ; \mathrm{p}=.025), \mathrm{CpG12}(\mathrm{r}=.42 ; \mathrm{p}=.016)$ and CpG13 $(\mathrm{r}=.55 ; \mathrm{p}=.001)$. Significant positive correlations were found between NMRs and methylation at CpG5 $(\mathrm{r}=.40 ; \mathrm{p}=.022)$ and CpG13 $(\mathrm{r}=.43 ; \mathrm{p}=.013)$.

3.4. SLC6A4 methylation, family cumulative risk and maltreatment experiences

As Baron and Kenny [47], Judd and Kenny [48], and James and Brett [49] suggested, one of the crucial steps in establishing mediation is that the predictor (CFR) is correlated with the mediator (NMRs). As no significant correlation emerged between CFR index and NMRs, we tested both CFR and NMRs as possible direct predictors of altered SLC6A4 DNA methylation patterns. Thus, two hierarchical multiple regressions were performed in order to test the role of CFR index, maltreatment and children's characteristics in explaining the DNA methylation level at CpG5 (Model 1) and CpG13 (Model 2). For both models, the CFR index was entered in Step 1; NMRs and years since the maltreatment occurred were entered in Step 2; children's gender and age were entered in Step 3. In order to adjust for multiple testing, we used the Benjamini-Hochberg false discovery rate procedure, setting an adjusted p-value of .05 [50].

Model 1 (CpG5) was significant overall ( $\mathrm{F}=10.44, \mathrm{p}<.001)$ and explained the $67 \%$ of the variance. Similarly, Model $2(\mathrm{CpG} 13)$ was significant overall $(\mathrm{F}=6.87, \mathrm{p}<.001)$ and explained the $57 \%$ of the variance. In both models, SLC6A4 DNA methylation was significantly explained by CFR index, NMRs and children's age. Higher CFR index, higher NMRs and higher children's age were significantly associated with higher methylation level at CpG5 and CpG13. The summary and coefficients for Model 1 and Model 2 are reported in Table 4. 
Table 4. Summary coefficients of regression models

\begin{tabular}{|c|c|c|c|c|c|c|c|c|c|}
\hline \multirow[b]{2}{*}{ Steps } & \multirow[b]{2}{*}{ Predictors } & \multicolumn{4}{|c|}{ Model 1 CpG5 } & \multicolumn{4}{|c|}{ Model 2 CpG13 } \\
\hline & & $R^{2}$ & $\begin{array}{c}R^{2} \\
\text { change }\end{array}$ & $\begin{array}{l}\text { Durbin- } \\
\text { Watson }\end{array}$ & $\beta$ & $R^{2}$ & $\begin{array}{c}R^{2} \\
\text { change }\end{array}$ & $\begin{array}{l}\text { Durbin- } \\
\text { Watson }\end{array}$ & $\beta$ \\
\hline Step 1 & & $.34^{* * *}$ & $.34^{* * *}$ & & & $.29^{* *}$ & $.29^{* *}$ & & \\
\hline & CFR & & & & $.58^{* * *}$ & & & & $.54^{* *}$ \\
\hline Step 2 & & $.43^{* * *}$ & .08 & & & $.40^{* *}$ & .11 & & \\
\hline & CFR & & & & $.52^{* *}$ & & & & $.47^{* *}$ \\
\hline & $\mathrm{N}$ of maltreatment experiences & & & & $.29 \#$ & & & & $.33^{*}$ \\
\hline & Years since the maltreatment occur & & & & .21 & & & & .04 \\
\hline Step 3 & & $.67^{* * *}$ & $.24^{* *}$ & 1.95 & & $.57^{* * *}$ & $.16^{*}$ & 1.62 & \\
\hline & CFR & & & & $.57^{* * *}$ & & & & $.51^{* *}$ \\
\hline & $\mathrm{N}$ of maltreatment experiences & & & & $.30^{*}$ & & & & $.31^{*}$ \\
\hline & Years since the maltreatment occur & & & & -.13 & & & & -.09 \\
\hline & Child gender & & & & .07 & & & & .091 \\
\hline & Child age & & & & $.50^{* *}$ & & & & $.40^{*}$ \\
\hline
\end{tabular}

Note. CFR = Cumulative Family Risk; ${ }^{*} p<.05 ;{ }^{* *} p<.01 ;{ }^{* * *} p<.001, \# p=.058$;

\section{Discussion}

The current work aimed to investigate the relationships among proximal family risk factors, child maltreatment experiences, and epigenetic patterns in children victims of maltreatment. We firstly hypothesized that a greater cumulative risk exposure to proximal family risk factors was associated with a greater number of maltreatment experiences. Contrary to our expectations, no significant correlation was found between these two variables in our sample. Although this appears a counterintuitive result, it should be noted that research has not provided conclusive results about this link yet. A literature review [51], that investigated the association between different risk factors, including family risk factors, and number child maltreatment experiences, reported equivocal or even contradictory findings for some specific risk factors. For example, inconsistent results were found when considering parental history of mental health problems, parental substance abuse, and domestic violence (factors also considered in the present study). In particular, some studies did not find an association between these factors and the number of child maltreatment experiences [52-54]. In their review White and colleagues [51] recommended to include several factors in the risk assessment of maltreatment recurrence such as household size, presence of grandparents or other source of family or social support, presence, and type of local services. Unfortunately, given the unavailability of this information, we were not able to consider these variables in the CFR index. Therefore, we cannot rule out that the lack of association observed in the present study could be due the fact that additional variables related to the family functioning would have provided a more comprehensive picture of proximal family risk factors.

Moreover, our results highlighted that, in children with a history of maltreatment, the severity of the family risk factors, and multiple maltreatment experiences directly contribute to explain, at least partially, the level of DNA methylation of SLC6A4 at the CpG5 and GpG13 sites, suggesting that SLC6A4 DNA methylation patterns might be affected 
by a combination of both direct (i.e., childhood maltreatment) and proximal (i.e., proximal family risk factors) variables. The strongest predictor of SLC6A4 DNA methylation was the CFR index, which explained the $34 \%$ of variance alone in the model with CpG5 as outcome and the $29 \%$ of variance alone in the model with CpG13 as outcome. One may wonder how these findings could explain the association between CFR and SLC6A4 DNA methylation in maltreated children. Several child maltreatment studies suggest that proximal family risk factors are associated with high level of parental stress [16,55] and variations in early parental care, often induced by high stress levels, result in altered neural, hormonal, cognitive, and behavioural responses in their offspring [56]. Moreover, highrisk contexts characterized by several proximal family risk factors (i.e., domestic violence, inappropriate parenting behaviour) are associated with intergenerational transmission by which parents affect their offspring's traits through genetics, social learning or other processes $[57,58]$, including epigenetic mechanisms [59,60]. Importantly, the CFR index range observed in this study varied between 0 to $7(\mathrm{M}=2.91)$ suggesting that even moderate levels of family risk factors might represent a critical condition that contributes to altered DNA methylation patterns [30]. Thus, a possible interpretation of our findings is that DNA methylation alterations in children with maltreatment history might be a result of exposure to proximal family risk factors (not necessarily at high levels) via intergenerational transmission. Although we cannot rule out that proximal family risk factors might have affected the offspring, without necessarily invoking epigenetics explanations of intergenerational transmission, evidence from the present study suggests that, together with childhood maltreatment, proximal family risk factors would expose the child to parental stress, resulting in epigenetic modifications associated with the serotoninergic system, which in turn plays a key role in regulating the HPA axis.

Furthermore, our results highlight the fact that higher number of maltreatment experiences predicted higher DNA methylation. This is in line with previous studies documenting that the cumulative experience of early childhood adversity is linked with SLC6A4 DNA methylation [25,28,31]. Notably, one study reported that SLC6A4 DNA methylation not only could be considered a biomarker of exposure to early life adversities, but it was also significantly associated with the cumulative number of traumatic event [61]. On the one hand, we can assume that SLC6A4 DNA methylation status may be considered as a biomarker for early maltreatment experiences, underscoring the possible role of SLC6A4 DNA methylation in the short- and long-term sequelae of the cumulative experience of different form of childhood maltreatments. On the other hand, it is important to note that the association between SLC6A4 DNA methylation and childhood maltreatment has not been consistently replicated in the literature and case-control studies offer contradictory findings of SLC6A4 methylation between trauma- and non-trauma-impacted groups [30,62]. Nonetheless, this result encourages further exploration of the role of SLC6A4 DNA methylation in accounting for gene-environment interactions and how it might modulate the development of later-life psychopathology.

Finally, we found that children's age was a significant predictor of SLC6A4 DNA methylation. There are several evidences that $\mathrm{CpG}$ dinucleotides located in the promoters of some genes become methylated with age [63-65]. In the pediatric population, a recent work observed an increased rate of age-associated DNA methylation changes, suggesting adjusting for age as a covariate in pediatric studies of DNA methylation [63]. Consequently, the significant effect in the present study may be due to the large age-range of our sample (from 8 months to 15 years). Our finding corroborates the importance to include age as a control variable in the analysis in childhood epigenetic studies.

The present study had limitations. First, we focused only on a specific gene, SLC6A4. Nonetheless, the methylation changes observed in this gene might be detected even in other genes involved in stress regulation (for example NR3C1). Further research is needed both by adopting a target gene approach, by considering other genes associated with early adverse events and stress regulation, and by adopting a genome-wide approach. Second, 
this study involved only a sample of children victims of maltreatment. It would be important to include a control sample of children without history of maltreatment to investigate further the extent of altered SLC6A4 DNA methylation. Third, in human studies, DNA methylation markers can only be evaluated in peripheral tissues (i.e., blood, salivary sample). Nonetheless, recent findings suggest that peripheral methylation levels correlate with those measured centrally [66], with buccal samples being the more closely aligned with the DNA methylation patterns in the brain [67]. Fourth, considering the cross-sectional nature of our study, we cannot exclude that SLC6A4 methylation status might have been changed during the residential care stay, before the DNA methylation was assessed. Therefore, future studies are warranted to employ a research design that includes different time points of DNA methylation evaluation. In addition, future studies should account for possible differences in terms of epigenetic patterns of diverse early adversities.

Notwithstanding these limitations, the study suggests that epigenetic mechanisms can be potential biomarkers, not only of childhood maltreatment experiences per sé, but also of proximal family risk factors. However, since at this stage it is not possible to assume causal evidence between family risk factors and DNA methylation in maltreated children, further larger-scale research focused on the association between adverse and dysfunctional family environment and epigenetic changes in children's victims of maltreatment are encouraged. First, we should consider the importance of clearly defining proximal family risk factors associated with specific kind of maltreatments in well-designed epigenetic studies. Second, more research is needed to establish the role of an adverse family environment on epigenetics, including potential protective factors, and the role of epigenetic moderation informed by individual differences in child resilience. Third, it would be important to improve and expand our knowledge of longitudinal and cumulative effects of the environment on the epigenome in children exposed to maltreatment. Finally, from a parental intervention point of view, it would be crucial to explore the impact that parenting intervention programs could have on children's DNA methylation [68].

\section{Conclusions}

While our findings cannot prove a causal relationship between family risk factors and DNA methylation in maltreated children, the present study adds new evidence, in line with recent views, of how the family environment can become biologically embedded through epigenetic changes and can "get under children's skins" [69,70]. These epigenetics vestiges remain even after the children are removed from their caregiver's care and placed in residential care, suggesting that, in conjunction with childhood maltreatment experiences, proximal family risk factors represent a critical condition contributing to an altered DNA methylation pattern in children. This might result in a relatively stable contribution to the establishment of long-term trajectories of less-than-optimal social-emotional development in these children.

Author Contributions: Conceptualization, F.C., E.M., R.M.; methodology, R.G., M.G.F., F.T.; formal analysis, R.G, M.V.; investigation, F.C., E.M; resources, A.T., M.G.B; data curation, A.C., M.V.; writing-original draft preparation, F.C., E.M., F.T.; writing - review and editing, R.M., A.C., A.T; visualization, M.G.B.; supervision, A.C., A.T., R.M.; project administration, F.C., R.M., A.T.; funding acquisition, A.T., R.M., and M.G.B. All authors have read and agreed to the published version of the manuscript.

Funding: This research was funded 5 per mille" funds for biomedical research to Francesco Craig and partially supported by the Italian Ministry of Health RC 2020 to Rosario Montirosso.

Acknowledgments: We are thankful to our colleagues and community workers who provided invaluable help for the enrollment of all the minors placed in the Maltreatment Clinical Unit (Ostuni) of the Scientific Institute IRCCS “Eugenio Medea" of Brindisi. This paper and the research would not have been possible without their exceptional support. 
Conflicts of Interest: The authors declare no conflict of interest

\section{References}

1. World Health Organization Child maltreatment Available online: https://www.who.int/news-room/fact-sheets/detail/child-maltreatment.

2. Hillis, S.; Mercy, J.; Amobi, A.; Kress, H. Global prevalence of past-year violence against children: A systematic review and minimum estimates. Pediatrics 2016.

3. CISMAI; Terre des Hommes II INDAGINE NAZIONALE SUL MALTRATTAMENTO DEI BAMBINI E DEGLI ADOLESCENTI IN ITALIA; 2020;

4. Afifi, T.O.; MacMillan, H.L.; Boyle, M.; Cheung, K.; Taillieu, T.; Turner, S.; Sareen, J. Child abuse and physical health in adulthood. Heal. Reports 2016.

5. Min, M.O.; Minnes, S.; Kim, H.; Singer, L.T. Pathways linking childhood maltreatment and adult physical health. Child Abus. Negl. 2013, doi:10.1016/j.chiabu.2012.09.008.

6. Perepletchikova, F.; Kaufman, J. Emotional and behavioral sequelae of childhood maltreatment. Curr. Opin. Pediatr. 2010.

7. Tran, N.K.; Van Berkel, S.R.; Van IJzendoorn, M.H.; Alink, L.R.A. The association between child maltreatment and emotional, cognitive, and physical health functioning in Vietnam. BMC Public Health 2017, doi:10.1186/s12889-017-4258-z.

8. Gilbert, R.; Widom, C.S.; Browne, K.; Fergusson, D.; Webb, E.; Janson, S. Burden and consequences of child maltreatment in high-income countries. Lancet 2009.

9. Belsky, J. The determinants of parenting: a process model. Child Dev. 1984, doi:10.1111/j.1467-8624.1984.tb00275.x.

10. Baldwin, H.; Biehal, N.; Allgar, V.; Cusworth, L.; Pickett, K. Antenatal risk factors for child maltreatment: Linkage of data from a birth cohort study to child welfare records. Child Abus. Negl. 2020, doi:10.1016/j.chiabu.2020.104605.

11. Sameroff, A.; Gutman, L.M.; Peck, S.C. Adaptation among youth facing multiple risks: Prospective research findings. In Resilience and Vulnerability: Adaptation in the Context of Childhood Adversities; 2003 ISBN 9780511615788.

12. Atzaba-Poria, N.; Pike, A.; Deater-Deckard, K. Do risk factors for problem behaviour act in a cumulative manner? An examination of ethnic minority and majority children through an ecological perspective. J. Child Psychol. Psychiatry Allied Discip. 2004, doi:10.1111/j.1469-7610.2004.00265.x.

13. Buehler, C.; Gerard, J.M. Cumulative Family Risk Predicts Increases in Adjustment Difficulties across Early Adolescence. J. Youth Adolesc. 2013, doi:10.1007/s10964-012-9806-3.

14. Chen, H.J. A cumulative family risk index model: Delinquency and academic performance among Han Chinese and Native Taiwanese students. Int. Soc. Work 2019, doi:10.1177/0020872818777787.

15. Casanueva, C.; Dolan, M.; Smith, K.; Ringeisen, H.; Dowd, K. Indicators of well-being among children in the united states child welfare system. In Proceedings of the Child Indicators Research; 2012.

16. Stith, S.M.; Liu, T.; Davies, L.C.; Boykin, E.L.; Alder, M.C.; Harris, J.M.; Som, A.; McPherson, M.; Dees, J.E.M.E.G. Risk factors in child maltreatment: A meta-analytic review of the literature. Aggress. Violent Behav. 2009.

17. Cicchetti, D.; Toth, S.L. Child Maltreatment and Developmental Psychopathology: A Multilevel Perspective. In Developmental Psychopathology; 2016.

18. Lanfumey, L.; Mongeau, R.; Cohen-Salmon, C.; Hamon, M. Corticosteroid-serotonin interactions in the neurobiological mechanisms of stress-related disorders. Neurosci. Biobehav. Rev. 2008.

19. Porter, R.J.; Gallagher, P.; Watson, S.; Young, A.H. Corticosteroid-serotonin interactions in depression: A review of the human evidence. Psychopharmacology (Berl). 2004.

20. Gaspar, P.; Cases, O.; Maroteaux, L. The developmental role of serotonin: News from mouse molecular genetics. Nat. Rev. Neurosci. 2003.

21. Karayol, R.; Medrihan, L.; Warner-Schmidt, J.L.; Fait, B.W.; Rao, M.N.; Holzner, E.B.; Greengard, P.; Heintz, N.; Schmidt, E.F. Serotonin receptor 4 in the hippocampus modulates mood and anxiety. Mol. Psychiatry 2021, doi:10.1038/s41380-020-00994$\mathrm{y}$.

22. Bocchio, M.; McHugh, S.B.; Bannerman, D.M.; Sharp, T.; Capogna, M. Serotonin, amygdala and fear: Assembling the puzzle. Front. Neural Circuits 2016.

23. Puig, M.V.; Gulledge, A.T. Serotonin and prefrontal cortex function: neurons, networks, and circuits. Mol. Neurobiol. 2011.

24. Hood, S.D.; Hince, D.A.; Robinson, H.; Cirillo, M.; Christmas, D.; Kaye, J.M. Serotonin regulation of the human stress response. Psychoneuroendocrinology 2006, doi:10.1016/j.psyneuen.2006.07.001.

25. Provenzi, L.; Giorda, R.; Beri, S.; Montirosso, R. SLC6A4 methylation as an epigenetic marker of life adversity exposures in humans: A systematic review of literature. Neurosci. Biobehav. Rev. 2016.

26. Nordquist, N.; Oreland, L. Serotonin, genetic variability, behaviour, and psychiatric disorders - A review. Ups. J. Med. Sci. 2010, doi:10.3109/03009730903573246.

27. Canli, T.; Lesch, K.P. Long story short: The serotonin transporter in emotion regulation and social cognition. Nat. Neurosci. 2007. 
28. Parade, S.H.; Huffhines, L.; Daniels, T.E.; Stroud, L.R.; Nugent, N.R.; Tyrka, A.R. A systematic review of childhood maltreatment and DNA methylation: candidate gene and epigenome-wide approaches. Transl. Psychiatry 2021.

29. Vijayendran, M.; Beach, S.R.H.; Plume, J.M.; Brody, G.H.; Philibert, R.A. Effects of Genotype and Child Abuse on DNA Methylation and Gene Expression at the Serotonin Transporter. Front. Psychiatry 2012, doi:10.3389/fpsyt.2012.00055.

30. Cecil, C.A.M.; Zhang, Y.; Nolte, T. Childhood maltreatment and DNA methylation: A systematic review. Neurosci. Biobehav. Rev. 2020.

31. Beach, S.R.H.; Brody, G.H.; Todorov, A.A.; Gunter, T.D.; Philibert, R.A. Methylation at 5HTT mediates the impact of child sex abuse on women's antisocial behavior: An examination of the iowa adoptee sample. Psychosom. Med. 2011, doi:10.1097/PSY.0b013e3181fdd074.

32. Kang, H.J.; Kim, J.M.; Stewart, R.; Kim, S.Y.; Bae, K.Y.; Kim, S.W.; Shin, I.S.; Shin, M.G.; Yoon, J.S. Association of SLC6A4 methylation with early adversity, characteristics and outcomes in depression. Prog. Neuro-Psychopharmacology Biol. Psychiatry 2013, doi:10.1016/j.pnpbp.2013.01.006.

33. Booij, L.; Richard, T.; Szyf, M.; Benkelfat, C. Genetic and early environmental influences on the serotonin system: Consequences for brain development and risk for psychopathology. J. Psychiatry Neurosci. 2015, doi:10.1503/jpn.140099.

34. Beach, S.R.H.; Dogan, M. V.; Brody, G.H.; Philibert, R.A. Differential impact of cumulative SES risk on methylation of protein-protein interaction pathways as a function of SLC6A4 genetic variation in African American young adults. Biol. Psychol. 2014, doi:10.1016/j.biopsycho.2013.10.006.

35. Timothy, A.; Benegal, V.; Shankarappa, B.; Saxena, S.; Jain, S.; Purushottam, M. Influence of early adversity on cortisol reactivity, SLC6A4 methylation and externalizing behavior in children of alcoholics. Prog. Neuro-Psychopharmacology Biol. Psychiatry 2019, doi:10.1016/j.pnpbp.2019.109649.

36. Appleyard, K.; Egeland, B.; van Dulmen, M.H.M.; Sroufe, L.A. When more is not better: The role of cumulative risk in child behavior outcomes. J. Child Psychol. Psychiatry Allied Discip. 2005, doi:10.1111/j.1469-7610.2004.00351.x.

37. Evans, G.W.; Kim, P.; Ting, A.H.; Tesher, H.B.; Shannis, D. Cumulative risk, maternal responsiveness, and allostatic load among young adolescents. Dev. Psychol. 2007, doi:10.1037/0012-1649.43.2.341.

38. Lamela, D.; Figueiredo, B. A Cumulative Risk Model of Child Physical Maltreatment Potential: Findings From a Community-Based Study. J. Interpers. Violence 2018, doi:10.1177/0886260515615142.

39. Montirosso, R.; Provenzi, L.; Fumagalli, M.; Sirgiovanni, I.; Giorda, R.; Pozzoli, U.; Beri, S.; Menozzi, G.; Tronick, E.; Morandi, F.; et al. Serotonin Transporter Gene (SLC6A4) Methylation Associates With Neonatal Intensive Care Unit Stay and 3Month-Old Temperament in Preterm Infants. Child Dev. 2016, doi:10.1111/cdev.12492.

40. Euser, E.M.; van IJzendoorn, M.H.; Prinzie, P.; Bakermans-Kranenburg, M.J. Prevalence of child maltreatment in the Netherlands. Child Maltreat. 2010, doi:10.1177/1077559509345904.

41. Li, S.; Zhao, F.; Yu, G. Childhood maltreatment and intimate partner violence victimization: A meta-analysis. Child Abus. Negl. 2019, doi:10.1016/j.chiabu.2018.11.012.

42. Whitten, T.; Dean, K.; Li, R.; Laurens, K.R.; Harris, F.; Carr, V.J.; Green, M.J. Earlier Contact with Child Protection Services Among Children of Parents With Criminal Convictions and Mental Disorders. Child Maltreat. 2021, doi:10.1177/1077559520935204.

43. Nguyen, L.H. The relationship between unemployment and child maltreatment: A county-level perspective in California. Child. Youth Serv. Rev. 2013, doi:10.1016/j.childyouth.2013.05.015.

44. Barnett, D.; Manly, J.T.; Cicchetti, D. Defining Child Maltreatment: The interface between policy and research. Adv. Appl. Dev. Psychol. Child Abus. Child Dev. Soc. Policy. 1993.

45. $\quad$ English, D.J.; Upadhyaya, M.P.; Litrownik, A.J.; Marshall, J.M.; Runyan, D.K.; Graham, J.C.; Dubowitz, H. Maltreatment's wake: The relationship of maltreatment dimensions to child outcomes. Child Abus. Negl. 2005, doi:10.1016/j.chiabu.2004.12.008.

46. Cicchetti, D.; Rogosch, F.A.; Thibodeau, E.L. The effects of child maltreatment on early signs of antisocial behavior: Genetic moderation by tryptophan hydroxylase, serotonin transporter, and monoamine oxidase A genes. Dev. Psychopathol. 2012, doi:10.1017/S0954579412000442.

47. Baron, R.M.; Kenny, D.A. The moderator-mediator variable distinction in social psychological research: Conceptual, strategic, and statistical considerations. J. Pers. Soc. Psychol. 1986, doi:10.1037//0022-3514.51.6.1173.

48. Judd, C.M.; Kenny, D.A. Process analysis: Estimating Mediation in Treatment Evaluations. Eval. Rev. 1981, doi:10.1177/0193841X8100500502.

49. James, L.R.; Brett, J.M. Mediators, moderators, and tests for mediation. J. Appl. Psychol. 1984, doi:10.1037/00219010.69.2.307.

50. Benjamini, Y.; Hochberg, Y. Controlling the False Discovery Rate: A Practical and Powerful Approach to Multiple Testing. J. R. Stat. Soc. Ser. B 1995, doi:10.1111/j.2517-6161.1995.tb02031.x.

51. White, O.G.; Hindley, N.; Jones, D.P.H. Risk factors for child maltreatment recurrence: An updated systematic review. Med. Sci. Law 2015.

52. Thompson, R.; Tabone, J.K. The impact of early alleged maltreatment on behavioral trajectories. Child Abus. Negl. 2010, doi:10.1016/j.chiabu.2010.06.006.

53. Kohl, P.L.; Jonson-Reid, M.; Drake, B. Time to leave substantiation behind: Findings from a national probability study. Child Maltreat. 2009, doi:10.1177/1077559508326030. 
54. Dorsey, S.; Mustillo, S.A.; Farmer, E.M.Z.; Elbogen, E. Caseworker assessments of risk for recurrent maltreatment: Association with case-specific risk factors and re-reports. Child Abus. Negl. 2008, doi:10.1016/j.chiabu.2007.06.006.

55. Timmer, S.G.; Borrego, J.; Urquiza, A.J. Antecedents of coercive interactions in physically abusive mother-child dyads. J. Interpers. Violence 2002, doi:10.1177/0886260502017008003.

56. Smith, K.E.; Pollak, S.D. Early life stress and development: potential mechanisms for adverse outcomes. J. Neurodev. Disord. 2020.

57. Bowers, M.E.; Yehuda, R. Intergenerational Transmission of Stress in Humans. Neuropsychopharmacology 2016.

58. Lomanowska, A.M.; Boivin, M.; Hertzman, C.; Fleming, A.S. Parenting begets parenting: A neurobiological perspective on early adversity and the transmission of parenting styles across generations. Neuroscience 2017.

59. Yehuda, R.; Daskalakis, N.P.; Bierer, L.M.; Bader, H.N.; Klengel, T.; Holsboer, F.; Binder, E.B. Holocaust Exposure Induced Intergenerational Effects on FKBP5 Methylation. Biol. Psychiatry 2016, doi:10.1016/j.biopsych.2015.08.005.

60. Tobi, E.W.; Lumey, L.H.; Talens, R.P.; Kremer, D.; Putter, H.; Stein, A.D.; Slagboom, P.E.; Heijmans, B.T. DNA methylation differences after exposure to prenatal famine are common and timing- and sex-specific. Hum. Mol. Genet. 2009, doi:10.1093/hmg/ddp353.

61. Koenen, K.C.; Uddin, M.; Chang, S.C.; Aiello, A.E.; Wildman, D.E.; Goldmann, E.; Galea, S. SLC6A4 methylation modifies the effect of the number of traumatic events on risk for posttraumatic stress disorder. Depress. Anxiety 2011, doi:10.1002/da.20825.

62. Neves, I.; Dinis-Oliveira, R.J.; Magalhães, T. Epigenomic mediation after adverse childhood experiences: a systematic review and meta-analysis. Forensic Sci. Res. 2021.

63. Ahuja, N.; Issa, J.P.J. Aging, methylation and cancer. Histol. Histopathol. 2000.

64. Dammann, R.; Li, C.; Yoon, J.H.; Chin, P.L.; Bates, S.; Pfeifer, G.P. Epigenetic inactivation of a RAS association domain family protein from the lung tumour suppressor locus 3p21.3. Nat. Genet. 2000, doi:10.1038/77083.

65. Burbee, D.G.; Forgacs, E.; Zöchbauer-Müller, S.; Shivakumar, L.; Fong, K.; Gao, B.; Randle, D.; Kondo, M.; Virmani, A.; Bader, S.; et al. Epigenetic inactivation of RASSF1A in lung and breast cancers and malignant phenotype suppression. J. Natl. Cancer Inst. 2001, doi:10.1093/jnci/93.9.691.

66. Agha, G.; Hajj, H.; Rifas-Shiman, S.L.; Just, A.C.; Hivert, M.F.; Burris, H.H.; Lin, X.; Litonjua, A.A.; Oken, E.; DeMeo, D.L.; et al. Birth weight-for-gestational age is associated with DNA methylation at birth and in childhood. Clin. Epigenetics 2016, doi:10.1186/s13148-016-0285-3.

67. Braun, P.R.; Han, S.; Hing, B.; Nagahama, Y.; Gaul, L.N.; Heinzman, J.T.; Grossbach, A.J.; Close, L.; Dlouhy, B.J.; Howard, M.A.; et al. Genome-wide DNA methylation comparison between live human brain and peripheral tissues within individuals. Transl. Psychiatry 2019, doi:10.1038/s41398-019-0376-y.

68. Hoye, J.R.; Cheishvili, D.; Yarger, H.A.; Roth, T.L.; Szyf, M.; Dozier, M. Preliminary indications that the Attachment and Biobehavioral Catch-up Intervention alters DNA methylation in maltreated children. Dev. Psychopathol. 2020, doi:10.1017/S0954579419001421.

69. Overbeek, G.; Creasey, N.; Wesarg, C.; Huijzer-Engbrenghof, M.; Spencer, H. When mummy and daddy get under your skin: A new look at how parenting affects children's DNA methylation, stress reactivity, and disruptive behavior. New Dir. Child Adolesc. Dev. 2020, doi:10.1002/cad.20362.

70. Craig, F.; Tenuta, F.; Rizzato, V.; Costabile, A.; Trabacca, A.; Montirosso, R. Attachment-related dimensions in the epigenetic era: A systematic review of the human research. Neurosci. Biobehav. Rev. 2021. 